\title{
Antigenic specificity of serological response in Chlamydia trachomatis urethritis detected by immunoblotting
}

\author{
R CEVENINI, F RUMPIANESI, V SAMBRI, M LA PLACA \\ From the Institute of Microbiology, University of Bologna, Ospedale S. Orsola, Bologna, Italy
}

SUMMARY Sera from 19 patients with Chlamydia trachomatis culture positive non-gonococcal urethritis were studied for the presence of antibodies to chlamydial proteins by immunoblotting. Ten $C$ trachomatis negative patients with non-gonococcal urethritis and 10 healthy controls were also studied. Acute phase sera from $C$ trachomatis positive patients with non-gonococcal urethritis reacted only with the major outer membrane protein whereas all the convalescent phase serum samples reacted with the major outer membrane protein and with a 60000 and a 62000 molecular weight protein. Some sera also reacted with a 45000 molecular weight protein. Five of 10 convalescent phase samples from patients with $C$ trachomatis negative non-gonococcal urethritis showed a reaction pattern comparable with that observed in convalescent sera from $C$ trachomatis positive patients with non-gonococcal urethritis. Sera from healthy seronegative subjects were negative by blotting.

Chlamydia trachomatis is an obligate intracellular parasite that causes a broad spectrum of diseases in man. Genital tract infections caused by $C$ trachomatis are now a source of major interest in sexually transmitted diseases. Consistent experimental evidence has already been obtained on the aetiological role of $C$ trachomatis in non-gonococcal urethritis in men. ${ }^{1}$

$C$ trachomatis isolates are grouped into 15 different immunotypes according to the microimmunofluorescence test of Wang and Grayston. ${ }^{2}$ Using microimmunofluorescence, $C$ trachomatis LGV2 serotype has also been shown to broadly cross react with other serotypes. ${ }^{3}$

The sodium dodecyl sulphate polyacrylamide gel electrophoresis (SDS-PAGE) analysis of the 15 immunotypes of $C$ trachomatis showed a remarkable similarity in protein profile of different serotypes. Preliminary data also suggest that several proteins contain common antigenic determinants. The major outer membrane antigen, a single protein that predominates in chlamydial outer membranes, seems to contain both species specific and subspecies specific determinants, and, possibly, type specific determinants. ${ }^{4}$ The 60000 and $62000(60-62 \mathrm{~K})$ proteins also seem to share species specific determinants. ${ }^{5}$ This

Accepted for publication 28 November 1985 investigation aimed to define the antigenic specificity of the antibody response of patients with $C$ trachomatis non-gonococcal urethritis and the time course of antibody production during infection. Sera from patients and controls were tested by SDS-PAGE immunoblotting, using purified elementary bodies of $C$ trachomatis LGV2 serotype as a single antigen.

\section{Material and methods}

C trachomatis LGV2 serotype (434/BU strain) was grown in LLC-MK2 cells, ${ }^{6}$ and elementary bodies were purified according to the technique of Caldwell et $a l,{ }^{7}$ as previously described. ${ }^{8}$ The sodium dodecyl sulphate-PAGE procedure of Laemli was used. ${ }^{9}$

\section{IMMUNOBLOTTING}

The immunoblot procedure of Towbin et al ${ }^{10}$ and of Bittner et al, ${ }^{11}$ as modified by Batteiger $e t$ al, ${ }^{12}$ was used. Briefly, electrophoretic transfer was done in 25 mM sodium phosphate $(\mathrm{pH} 7.3)$ at 27 volts $(0.9$ to 1.0 ampere) for two hours at $20^{\circ} \mathrm{C}$ to HAHY Millipore nitrocellulose paper with Trans blot cell (Bio-Rad Laboratories, Richmond, California, United States). After transfer the nitrocellulose paper was incubated in $50 \mathrm{mM}$ sodium phosphate, $0 \cdot 15 \mathrm{M}$ sodium chloride, $0.02 \%$ sodium nitrate containing $3 \%$ bovine serum albumin (BSA) for 30 minutes. 


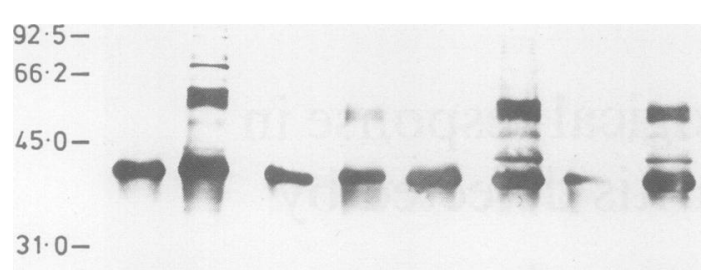

$21 \cdot 5-$

$14 \cdot 4-$

Fig. 1 Immunoblot pattern of sera from four patients with $C$ trachomatis non-gonococcal urethritis. Lanes $a, c, e, g$ represent acute phase; lanes $b, d, f, h$ represent convalescent phase, respectively, of each patient. Purified $C$ trachomatis (LGV2 serotype) elementary bodies were applied. Position and molecular weight of markers are indicated on the left.

The nitrocellulose paper was then incubated with the patient's serum, diluted $1 / 20$ in phosphate buffered saline containing 3\% BSA for 16 hours on a rocker platform. The nitrocellulose paper was washed three times for 10 minutes with phosphate buffered saline, followed by incubation with peroxidase labelled rabbit immunoglobulins to human IgG (Dako, Copenhagen, Denmark), and diluted 1/400 in phosphate buffered saline for two hours at room temperature. The nitrocellulose paper was then washed three times for 10 minutes with phosphate buffered saline and transferred to distilled water. The immunoblots were developed with a solution of $40 \mathrm{mg}$ benzidine (Fluka AG, Buchs, Switzerland) dissolved in $4 \mathrm{ml}$ acetone, $96 \mathrm{ml}$ phosphate buffered saline, and $0.1 \mathrm{ml}$ hydrogen peroxide from $33 \%$ stock solution. After development the blots were rinsed with distilled water and photographed.
Cevenini, Rumpianesi, Sambri, La Placa CHLAMYDIAL SEROLOGY

The presence of IgG and IgM antibodies to $C$ trachomatis was investigated by a single antigen immunofluorescence test using $C$ trachomatis LGV2 serotype $\stackrel{\vec{S}}{ }$ according to the technique of Richmond and Caul, ${ }^{13} \mathrm{C}$ as previously described. ${ }^{14}$

Nineteen men with $C$ trachomatis culture positive non-gonococcal urethritis were studied. Their sera $\mathbb{Q}$ were part of a study on the aetiology of nongonococcal urethritis performed in our laboratory. क Sera from four patients were available both before $\vec{\circ}$ treatment with antibiotics-that is, during the acute $\vec{\overrightarrow{ }}$ stage of infection when the urethral swab was $\stackrel{\circ}{\omega}$ obtained for culture-and during recovery-that is 홍 after the 10 day treatment. Only the later serum sam- $\omega$ ple was available from 15 patients. Sera from $10 C$ trachomatis negative patients with non-gonococcal $\dot{\omega}$ urethritis and 10 healthy subjects were also studied as $N$ controls.

\section{Results}

Fig. 1 shows the SDS-PAGE pattern of $C$ trachomatis $\stackrel{\circ}{\frac{1}{丂}}$ antigens obtained by immunoblotting with acute $\vec{\theta}$ (lanes a, c, e, g) and convalescent (lanes b, d, f, h) phase sera from four patients with $C$ trachomatis nongonococcal urethritis. Acute phase sera reacted only with the major outer membrane protein, whereas those of the convalescent phase reacted with the major outer membrane protein and with $60 \mathrm{~K}, 62 \mathrm{~K}$, \% and $45 \mathrm{~K}$ proteins. Some convalescent phase sera also $\triangle$ reacted with other proteins. Fig. 2 shows the SDS- $\vec{\circ}$ PAGE pattern obtained by immunoblotting with 3 convalescent phase sera from 15 patients with $C$ trachomatis non-gonococcal urethritis. All sera reacted with the major outer membrane protein and with $60 \mathrm{~K}$ and $62 \mathrm{~K}$ proteins. Some sera (lanes $\mathrm{a}, \mathrm{b}, \mathbf{j}, \mathbf{k}, \mathbf{1}, \mathbf{n}$ ) also reacted with $45 \mathrm{~K}$ protein and sometimes with other proteins.

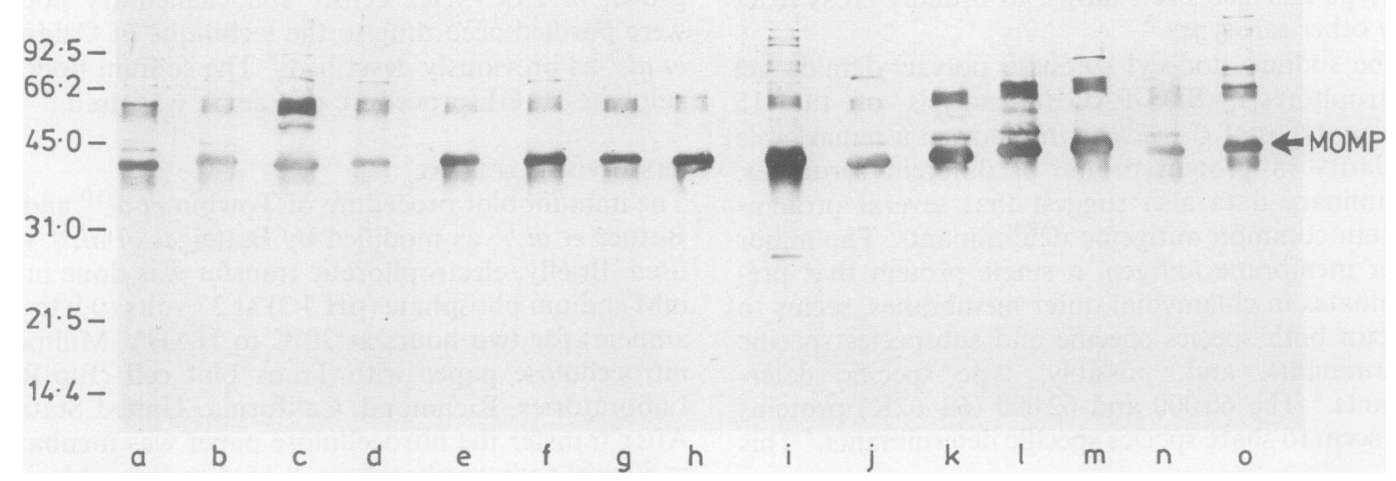

Fig. 2 Reaction of convalescent phase sera from 15 patients with C trachomatis non-gonococcal urethritis, with purified elementary bodies of $C$ trachomatis. 
All the acute phase sera were $C$ trachomatis IgG (titre $\geqslant 32$ ) and IgM (titre $\geqslant 16$ ) positive by immunofluorescence, whereas the convalescent phase sera were $C$ trachomatis IgG positive and IgM negative.

Of $10 \mathrm{C}$ trachomatis culture negative patients with non-gonococcal urethritis, five with IgG antibodies to $C$ trachomatis by immunofluorescence were also positive by blotting. The reaction patterns of these five sera were almost comparable with those observed in convalescent phase sera from culture positive patients with non-gonococcal urethritis (data not shown). Sera from $C$ trachomatis sero negative healthy subjects did not react against $C$ trachomatis proteins (data not shown).

\section{Discussion}

In a previous paper Caldwell et al $^{7}$ suggested that the major outer membrane protein is one of the primary antigens recognised after animal immunisation with viable or whole chlamydial elementary bodies. Our investigation of men with $C$ trachomatis nongonococcal urethritis supports this finding, showing that the very early response against $C$ trachomatis antigens in patients with non-gonococcal urethritis occurs against the major outer membrane protein. Later, the humoral response is against the $60 \mathrm{~K}-62 \mathrm{~K}$ proteins, often against the $45 \mathrm{~K}$ protein, ${ }^{5}$ and possibly, other proteins. Sera from the same patients collected from two months to one year after the onset of the infection (data not reported) showed the same reactivity against the major outer membrane protein and the $60 \mathrm{~K}$ and $62 \mathrm{~K}$ proteins. Thus the presence of antibodies against both the $60-62 \mathrm{~K}$ proteins and the major outer membrane protein seems to correlate well with current or past $C$ trachomatis infections, while antibodies directed only against the major outer membrane protein seem to correlate with current primary infection at an early stage. Major outer membrane protein reactivity was not found in any of the serologically negative samples examined.

In this study a single antigen preparation was used for the detection of antichlamydial antibody. The LGV2 serotype was chosen because of its reported broad antigenic cross reactivity. ${ }^{3}$ All the 19 sera from patients with chlamydial non-gonococcal urethritis reacted with LGV2 elementary bodies.

Although $C$ trachomatis isolates from these 19 patients were not typed, our data seem to be consistent with the results obtained by Newhall et al ${ }^{5}$ and Stephens et al, ${ }^{15}$ who showed the presence of species specific determinants in the major outer membrane protein, in addition to subspecies and type specific epitopes on each of the 15 major outer membrane proteins of $C$ trachomatis. All our serum samples from patients with non-gonococcal urethritis also reacted in the late stage of infection with the $60 \mathrm{~K}$ and $62 \mathrm{~K}$ proteins, supporting the previous finding ${ }^{5}$ that there are species specific determinants on these proteins.

We believe that the application of the immunoblot technique, which at present seems to be reasonably simple to perform, may provide a useful addition to the current serological methods for the study of chlamydial infections. In particular, the results from our study suggest that, at an early stage, primary infection by $C$ trachomatis in patients with non-gonococcal urethritis may be identified by the typical reactivity of sera with chlamydial antigens, as the major outer membrane protein at this stage of infection is the only reacting antigen.

We thank Mrs Franca Balboni for typing the manuscript.

\section{References}

${ }^{1}$ Schachter J, Grossman M. Chlamydial infections. Annu Rev Med 1981;32:45-61.

${ }^{2}$ Wang SP, Grayston T. Human serology in Chlamydia trachomatis infections with microimmunofluorescence. J Infect Dis 1974; 130:388-97.

${ }^{3}$ Thomas BJ, Reeve P, Oriel P. Simplified serological test for antibodies to Chlamydia trachomatis. J Clin Microbiol 1976;4:6-10.

${ }^{4}$ Caldwell HD, Schachter J. Antigenic analysis of the major outer membrane protein of Chlamydia spp. Infect Immun 1982; 85:1024-31.

${ }^{5}$ Newhall WJ, Batteiger B, Jones RB. Analysis of the human serological response to proteins of Chlamydia trachomatis. Infect Immun 1982;38:1181-9.

${ }^{6}$ Cevenini R, Rumpianesi F, Donati M, Sarov I. A rapid immunoperoxidase assay for the detection of specific IgG antibodies to Chlamydia trachomatis. J Clin Pathol 1983;36:353-6.

${ }^{7}$ Caldwell HD, Kromhout J, Schachter J. Purification and partial characterization of the major outer membrane protein of Chlamydia trachomatis. Infect Immun 1981;31:1161-76.

${ }^{8}$ Cevenini R, Sarov I, Rumpianesi F, Donati M, Melega C. Serum specific IgA antibody to Chlamydia trachomatis in patients with chlamydial infections detected by ELISA and immunofluorescence test. J Clin Pathol 1984;37:686-91.

${ }^{9}$ Laemli UK. Cleavage of structural proteins during the assembly of the head of bacteriophage T4. Nature (London) 1970;227:680-5.

${ }^{10}$ Towbin H, Staehelin T, Gordon J. Electrophoretic transfer of proteins from polyacrylamide gels to nitrocellulose sheets: procedure and some applications. Proc Natl Acad Sci USA 1979;76:4350-4.

${ }^{11}$ Bittner MP, Kupferer P, Morris CF. Electrophoretic transfer of proteins and nucleic acids from slab gels to diazobenzyloxymethyl cellulose or nitrocellulose sheets. Anal Biochem 1980;102:459-71.

${ }^{12}$ Batteiger B, Newhall WJ, Jones RB. The use of Tween-20 as blocking agent in the immunological detection of proteins transferred to nitrocellulose membranes. J Immunol Methods 1982; 55:297-307.

${ }^{13}$ Richmond SJ, Caul EO. Flourescent antibody studies in chlamydial infections. J Clin Microbiol 1975;1:345-52.

${ }^{14}$ Cevenini $R$, La Placa M. Chlamydial infections in Italy. Sex Transm Dis 1981;8:349-52.

${ }^{15}$ Stephens RS, Tam MR, Kuo CC, Nowinski RC. Monoclonal antibodies to Chlamydia trachomatis: antibody specificities and antigen characterization. J Immunol 1982;128:1083-9.

Requests for reprints to: Dr R Cevenini, Institute of Microbiology, Ospedale S. Orsola, Via Massarenti 9, 40138 Bologna, Italy. 